\title{
Ovarian Cancer Treatment Stratification Using Ex Vivo Drug Sensitivity Testing
}

\author{
INES LOHSE ${ }^{1,2,3^{*}}$, DIANA J. AZZAM ${ }^{1,2,3^{*}}$, HASSAN AL-ALI ${ }^{4,5,6,7}$, CLAUDE-HENRY VOLMAR ${ }^{1,2,3}$, \\ SHAUN P. BROTHERS ${ }^{1,2,3}$, TAN A. INCE ${ }^{4,8}$ and CLAES WAHLESTEDT ${ }^{1,2}$ \\ ${ }^{1}$ Center for Therapeutic Innovation, Miller School of Medicine, University of Miami, Miami, FL, U.S.A.; \\ ${ }^{2}$ Department of Psychiatry and Behavioral Sciences, \\ Miller School of Medicine, University of Miami, Miami, FL, U.S.A.; \\ ${ }^{3}$ Molecular Therapeutics Shared Resource, Sylvester Comprehensive Cancer Center, \\ University of Miami, Miami, FL, U.S.A.; \\ ${ }^{4}$ Sylvester Comprehensive Cancer Center, University of Miami, Miami, FL, U.S.A.; \\ ${ }^{5}$ Miami Project to Cure Paralysis, Miller School of Medicine, University of Miami, Miami, FL, U.S.A.; \\ ${ }^{6}$ Department of Neurological Surgery, Miller School of Medicine, University of Miami, Miami, FL, U.S.A.; \\ ${ }^{7}$ Peggy and Harold Katz Drug Discovery Center, Department of Medicine, \\ Miller School of Medicine, University of Miami, Miami, FL, U.S.A.; \\ ${ }^{8}$ Department of Pathology and Interdisciplinary Stem Cell Institute, \\ Miller School of Medicine, University of Miami, Miami, FL, U.S.A.
}

\begin{abstract}
Background: Treatment options for patients with platinum-resistant ovarian cancer are generally palliative in nature and rarely have realistic potential to be curative. Because many patients with recurrent ovarian cancer receive aggressive chemotherapy for prolonged periods, sometimes continuously, therapy-related toxicities are a major factor in treatment decisions. The use of ex vivo drug sensitivity screens has the potential to improve the treatment of patients with platinum-resistant ovarian cancer by providing personalized treatment plans and thus reducing toxicity from unproductive therapy attempts. Materials and Methods: We evaluated the treatment responses of a set of six earlypassage patient-derived ovarian cancer cell lines towards a set of 30 Food and Drug Administration-approved chemotherapy drugs using drug-sensitivity testing. Results:
\end{abstract}

This article is freely accessible online.

*These Authors contributed equally to this work.

Correspondence to: Claes Wahlestedt, Leonard M. Miller Professor, Director, Center for Therapeutic Innovation (CTI), Associate Dean for Therapeutic Innovation, Vice Chair for Research, Dept. Psychiatry and Behavioral Sciences, University of Miami Miller School of Medicine, 1501 NW 10th Ave, Miami, FL 33136, U.S.A. Tel: +1 3052437694, e-mail: cwahlestedt@med.miami.edu

Key Words: Ovarian cancer, ex vivo drug sensitivity screening, precision medicine.
We observed a wide range of treatment responses of the cell lines. While most compounds displayed vastly different treatment responses between cell lines, we found that some compounds such as docetaxel and cephalomannine reduced cell survival of all cell lines. Conclusion: We propose that ex vivo drug-sensitivity screening holds the potential to greatly improve patient outcomes, especially in a population where multiple continuous treatments are not an option due to advanced disease, rapid disease progression, age or poor overall health. This approach may also be useful to identify potential novel therapeutics for patients with ovarian cancer.

Ovarian cancer is the fifth most common cause of cancer deaths among women and accounts for more deaths than any other cancer of the female reproductive system, including breast cancer $(1,2)$. Ovarian cancer is more prevalent in older women ( $\geq 65$ years), a patient population that also has lower survival rates when compared to younger patients. If detected at early stages, patient survival is approximately $92 \%$. However, only $15 \%$ of all patients with ovarian cancer are diagnosed early, resulting in overall 5-year survival rates of around $45 \%(1,2)$. Standard treatment consists of surgery and systemic chemotherapy with a combination of a platinum compound and a taxane. While the majority of patients achieve remission in response to such combination treatments, $70 \%$ eventually experience relapse with a platinum-resistant tumor, at which point there are few treatment options (1-10).

Precision medicine approaches using ex vivo drugsensitivity testing (DST) have recently received attention in 
Table I. Compound library for ex vivo drug-sensitivity testing. All listed agents are Food and Drug Administration-approved and classified according to mechanism of action where available.

\begin{tabular}{ll}
\hline Class & Compound \\
\hline Antimetabolites & Cladrabine, clofarabine, gemcitabine/Gemzar \\
Antimitotics & Cephalomannine, docetaxel, paclitaxel, vincristine \\
lmmunomodulators & Mycophenolate \\
Kinase inhibitors & Afatinib, dasatinib, erlotinib, lbrutinib, ponatinib \\
Rapalogs & Everolimus, sirolimus \\
Topoisomerase 1/2 inhibitors & Camptothecin, daunorubicin, epirubicin, ldarubicin, lrinotecan, mitoxantrone, teniposide, topotecan \\
Other & Anagrelide, disulfiram, fluvastatin, doxorubicin, simvastatin \\
\hline
\end{tabular}

the cancer research community as part of institutional personalized medicine initiatives (11-14). To date, most efforts using ex vivo screening have concentrated on hematological cancers such as acute myeloid leukemia (AML) $(13,15-18)$. This is mostly due to the lack of available tumor biopsies at the time of therapeutic need and of low numbers of viable cells from core biopsies.

However, advances in drug-screening technologies and DST analysis algorithms have significantly improved the availability of this precision medicine platform for use in solid tumors such as ovarian cancer.

\section{Materials and Methods}

Patient-derived ovarian cancer cell lines. The patient-derived ovarian cancer cell lines (C1P, C5X, E1P, E3X, P5X and P9A1) and normal control cell line (OCE1) were established and cultured as described previously (19). Briefly, the ovarian cancer cell lines were maintained as described before (19) in Ovarian Carcinoma Modified Ince medium from Live Tissue Culture Service Center (LTCC, University of Miami, Miami, FL, USA). The normal ovarian epithelium (OCE1) culture was maintained in WIT-Fo culture medium as described before (20), also available from LTCC.

This study examined two clear-cell (C1P and C5X), two endometrioid (E1P and E3X) and two papillary serous (P5X and P9A1) primary ovarian cancer cell cultures. These ovarian cancer cells recapitulate the expected subtype-specific molecular features of human ovarian cancer. Cultures of papillary serous ovarian cancer cells express paired box 8 (PAX8), Wilms tumor protein 1 (WT1), p16, consistent with the serous phenotype. In contrast, clear-cell cultures are negative for WT1, but positive for hepatocyte nuclear factor 1-beta (HNF1B), specific for clear-cell phenotype. Serous ovarian cancer is typically associated with $p 53$ mutations and non-serous cancer with phosphoinositide 3-kinase (PI3K) mutations; the P5X cell line has a p53 (Y236N) mutation; in contrast $\mathrm{C} 1 \mathrm{P}$ and $\mathrm{E} 1 \mathrm{P}$ have $P I 3 K(\mathrm{O} 546 \mathrm{~L}$, p539R and E545G) mutations. We also previously showed that when implanted into immunocompromised mice, P5X, P9A1, C5X and E1P cells recapitulate their respective serous, clear-cell and endometrioid morphologies (19). Based on mRNA expression, these cell lines form two different clusters: The P9A1, C1P, and E3X co-cluster (C1) correlates with poor outcome and relative taxol/platin resistance, and the P5X, C5X and E1P co-cluster (C2) correlates with better outcome and relative taxol/platin sensitivity.
Table II. Drug-sensitivity scoring (DSS) and half-maximal effective concentration $\left(E C_{50}\right)$ values for the OCE1 cell line.

\begin{tabular}{|c|c|c|}
\hline Compound name & $\mathrm{EC}_{50}(\mu \mathrm{M})$ & DSS \\
\hline Afatinib & 5.55 & 19.61 \\
\hline Dasatinib & 0.05 & 16.84 \\
\hline Sirolimus & 0.02 & 0.17 \\
\hline Everolimus & 0.01 & 1.28 \\
\hline Docetaxel & 0.01 & 9.17 \\
\hline Gemzar & 49.82 & 21.38 \\
\hline Cladrabine & 0.18 & 7.81 \\
\hline Doxorubicin & 0.27 & 27.61 \\
\hline Clofarabine & 0.46 & 10.93 \\
\hline Epirubicin $\mathrm{HCl}$ & 0.22 & 30.39 \\
\hline Idarubicin $\mathrm{HCl}$ & 0.99 & 21.60 \\
\hline Topotecan $\mathrm{HCl}$ & 8.74 & 16.55 \\
\hline Vincristine & 0.01 & 3.44 \\
\hline Camptothecin & 0.83 & 25.09 \\
\hline Ponatinib & 3.05 & 13.38 \\
\hline Mycophenolate mofetil & 1.15 & 1.06 \\
\hline Disulfiram & $\mathrm{n} / \mathrm{a}$ & $\mathrm{n} / \mathrm{a}$ \\
\hline Gemcitabine & 0.18 & 21.58 \\
\hline Teniposide & 11.64 & 2.92 \\
\hline Simvastatin & 1445.06 & 5.24 \\
\hline Fluvastatin sodium & 1.10 & 8.01 \\
\hline OSI-420 & 0.49 & 9.26 \\
\hline Irinotecan $\mathrm{HCl}$ trihydrate & 1.43 & 2.05 \\
\hline Cephalomannine & 0.06 & 6.80 \\
\hline Mitoxantrone $\mathrm{HCl}$ & 1.13 & 20.95 \\
\hline Mycophenolic & 974.37 & 2.99 \\
\hline Ibrutinib & 0.78 & 4.93 \\
\hline Daunorubicin $\mathrm{HCl}$ & 0.36 & 28.30 \\
\hline Anagrelide $\mathrm{HCl}$ & 270726.9 & 2.89 \\
\hline Paclitaxel & 0.01 & 11.32 \\
\hline
\end{tabular}

DST. In order to evaluate the utility of the ex vivo DST platform in ovarian cancer, we tested a set of six low-passage patient-derived ovarian cancer cell lines of different cellular origin. DST was performed as described previously (15). Briefly, the 30 Food and Drug Administration (FDA)-/European Medicines Agency-approved anticancer drugs in the compound library cover a variety of targets and pathways relevant to cancer in general and ovarian cancer specifically (Table I). 


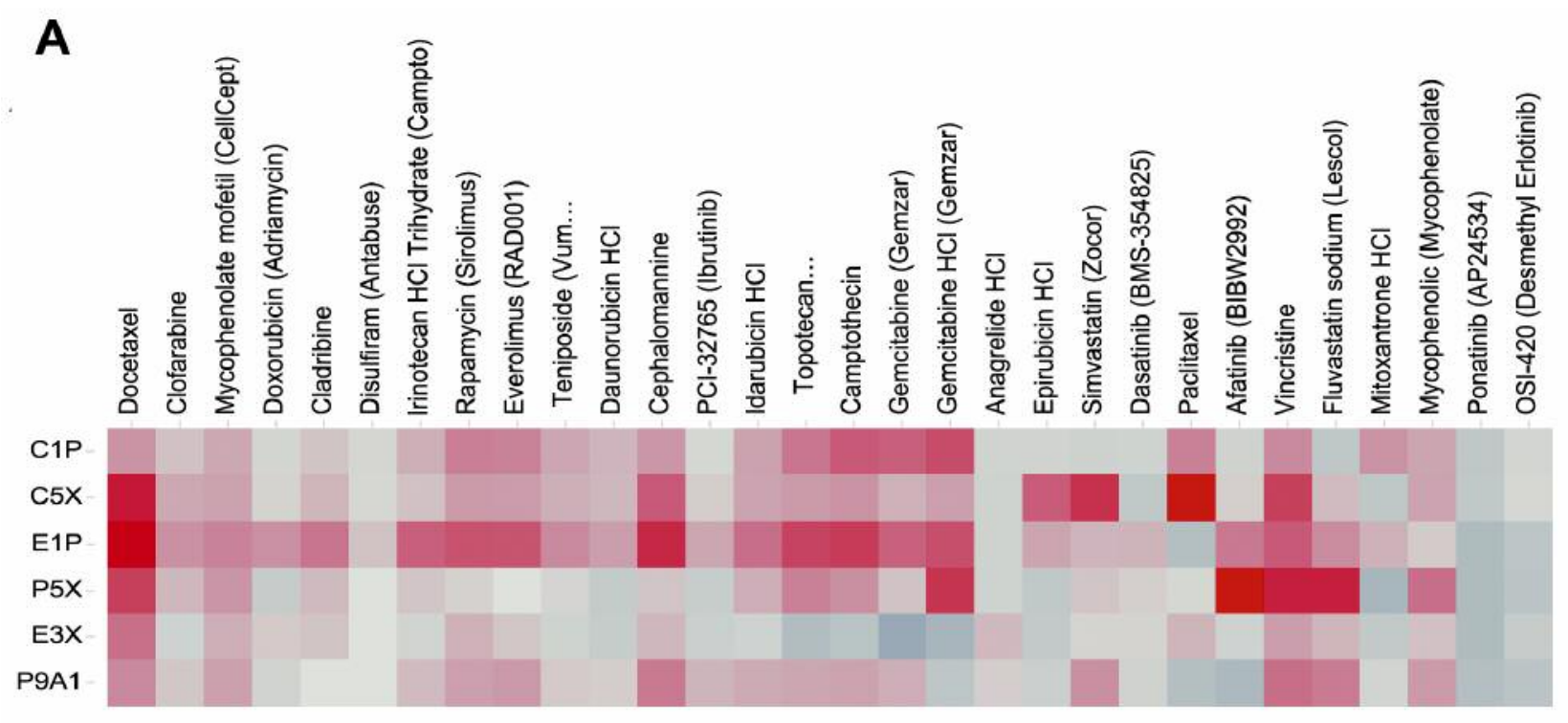

B

Docetaxel

C

Gem citabine
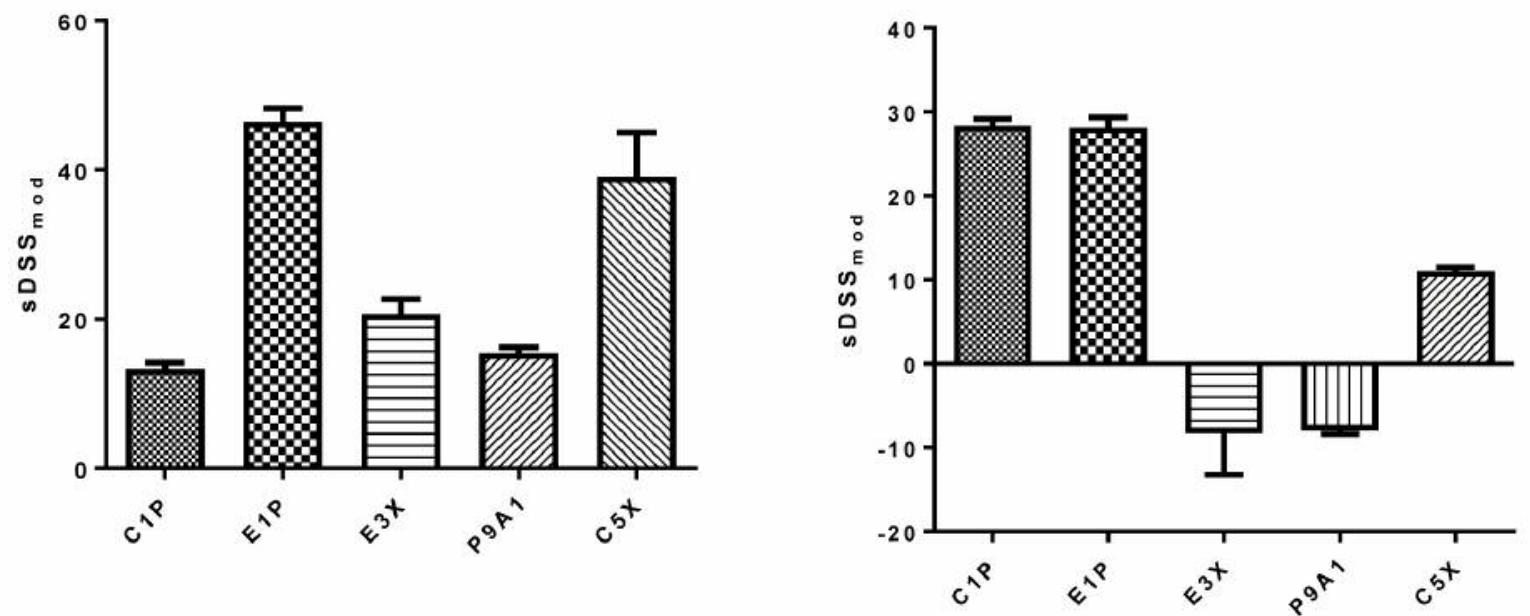

Figure 1. Ex-vivo drug-sensitivity testing. A: The heatmap of modified drug-sensitivity scoring (sDSSmod) profiles revealed a large variability in both the direction and magnitude of drug responses in the ovarian cancer cell lines tested. The sDSS ${ }_{\text {mod }}$ profile for each cell line is depicted with all drugs that had a score of more than +5 or less than -5 in at least one cell line (drugs that had no effect on all cell lines were excluded). Cell lines and drugs were clustered using hierarchical clustering with a Tanimoto distance metric. Red indicates a positive sDSS ${ }_{\text {mod }}$ score, while blue indicates a negative $s D S S_{\text {mod }}$ score. $s D S S_{\text {mod }}$ scores in response to treatment with docetaxel (B) and gemcitabine (Gemzar) $(C)$. Data are the means $\pm S E M$.

All compounds were dissolved in $100 \%$ dimethyl sulfoxide (DMSO) and tested in duplicate using a 10-point 1:3 dilution series starting at a nominal test concentration of $10 \mu \mathrm{M}(20,000$-fold concentration range). One thousand patient-derived mononuclear cells were seeded per well in 384-well micro-titer plates and incubated in the presence of compounds in a humidified environment at $37^{\circ} \mathrm{C}$ and $5 \% \mathrm{CO}_{2}$. After 72 hours of treatment, cell viability was assessed by measuring ATP levels via bioluminescence (CellTiterGlo; Promega, Madison, WI, USA) and dose-response curves were generated for each compound. Interpretation of curve parameters was performed according to the modified drug-sensitivity scoring $\left(\mathrm{DSS}_{\mathrm{mod}}\right)$ function we previously developed (15). As a final step, the selective $\mathrm{DSS}_{\text {mod }}\left(\mathrm{sDSS}_{\mathrm{mod}}\right)$ for each drug in each patient screen was calculated according to the formula: $\mathrm{sDSS}_{\mathrm{mod}}=\mathrm{DSS}_{\text {mod }}$ (cancer cells) - DSS $_{\text {mod }}$ (normal cells). Given in this way, $\mathrm{sDSS}_{\text {mod }}$ incorporates information on each drug's potency, efficacy, effect range and therapeutic index, making it possible to prioritize compounds over multiple parameters using a single numerical metric. In addition, this methodology allows compounds to be ranked by cancer-selective efficacy for each individual patient. For example, a large positive $\mathrm{sDSS}_{\text {mod }}$ means that a compound is highly selective for ovarian cancer cells over normal cells in a given sample (favorable scenario), while a large negative score means that the cells are likely to be resistant to the treatment (unfavorable scenario). 


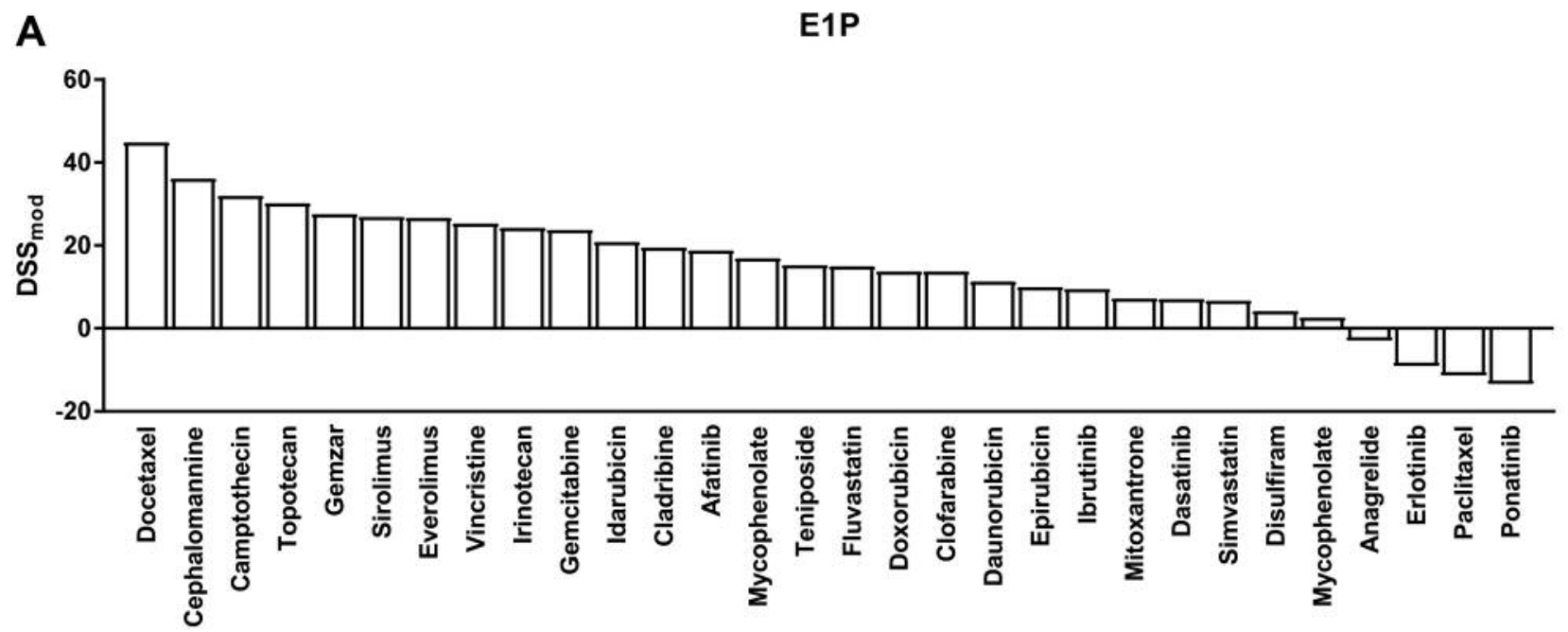

B

E3X

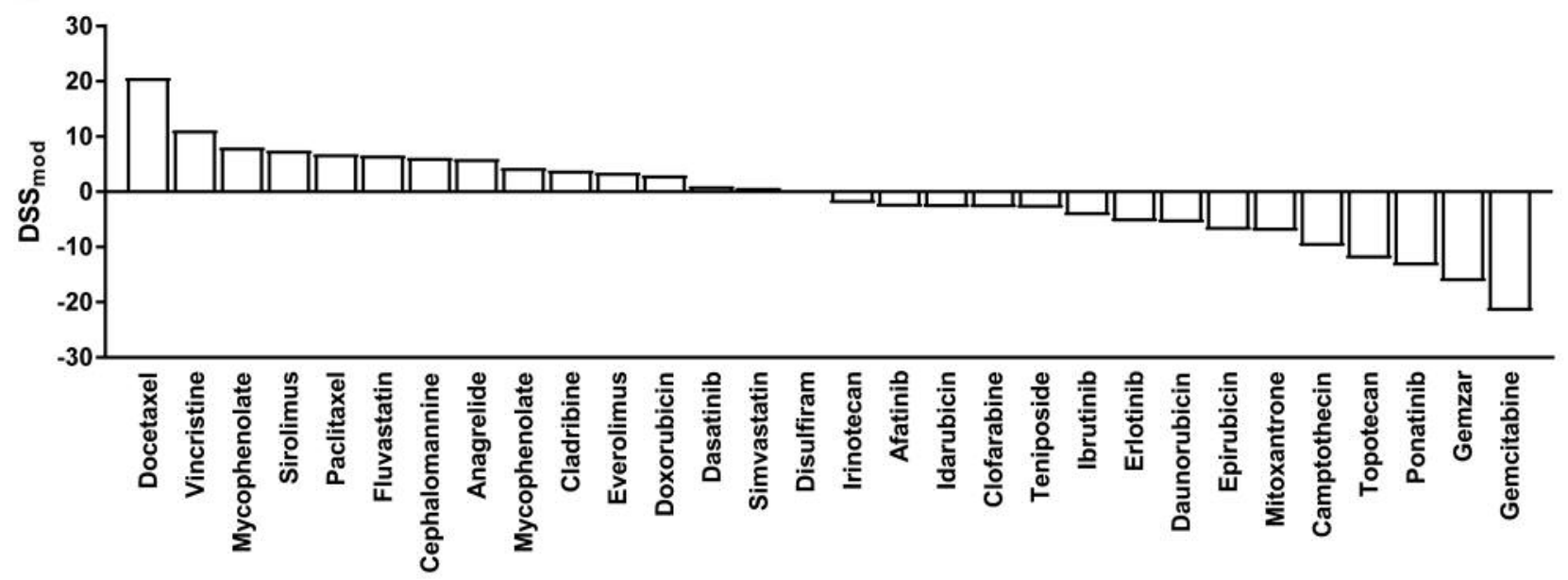

Figure 2. Individual screening results. Bar graphs of clinically actionable drug responses for endometrioid cancer cell lines E1P (A) and E3X (B).

All calculations and scoring routines were carried out in MatLab and additional curve fitting and statistical analyses were performed in GraphPad prism (Version 7.02; GraphPad Software, San Diego, CA, USA). ANOVA with Bonferroni post-hoc testing for multiple comparisons was used for the analysis of differences between different cell lines.

\section{Results}

DST of normal ovarian epithelium. The normal ovarian epithelium cell line OCE1 was established and immortalized as described previously (19). Merritt et al. demonstrated that this cell line expresses cell-surface markers and displays an expression profile consistent with the ovarian surface/inclusion cyst epithelium (19). OCE1 cells displayed submicromolar sensitivity to the majority of compounds
(Table II). These cells showed particular sensitivity to the rapalogs everolimus and sirolimus (Table I). Sensitivity to other compound classes such as topoisomerase 1/2 inhibitors were mixed and compound specific. The drug sensitivity results obtained from the normal ovarian epithelium cell line serves as a baseline for the calculation of the $\mathrm{sDSS}_{\bmod }$ values of patient-derived ovarian cancer cell lines.

DST of patient-derived ovarian cancer cell lines. Similar to what we previously observed in AML, the tested cell lines, derived from different patients, displayed a wide variety of treatment responses (Figure 1). Three of the tested compounds (docetaxel, vincristine and cephalomannine) displayed activity in all of the tested lines; however, the magnitude of response differed significantly (Figure 1A and B). Treatment responses 


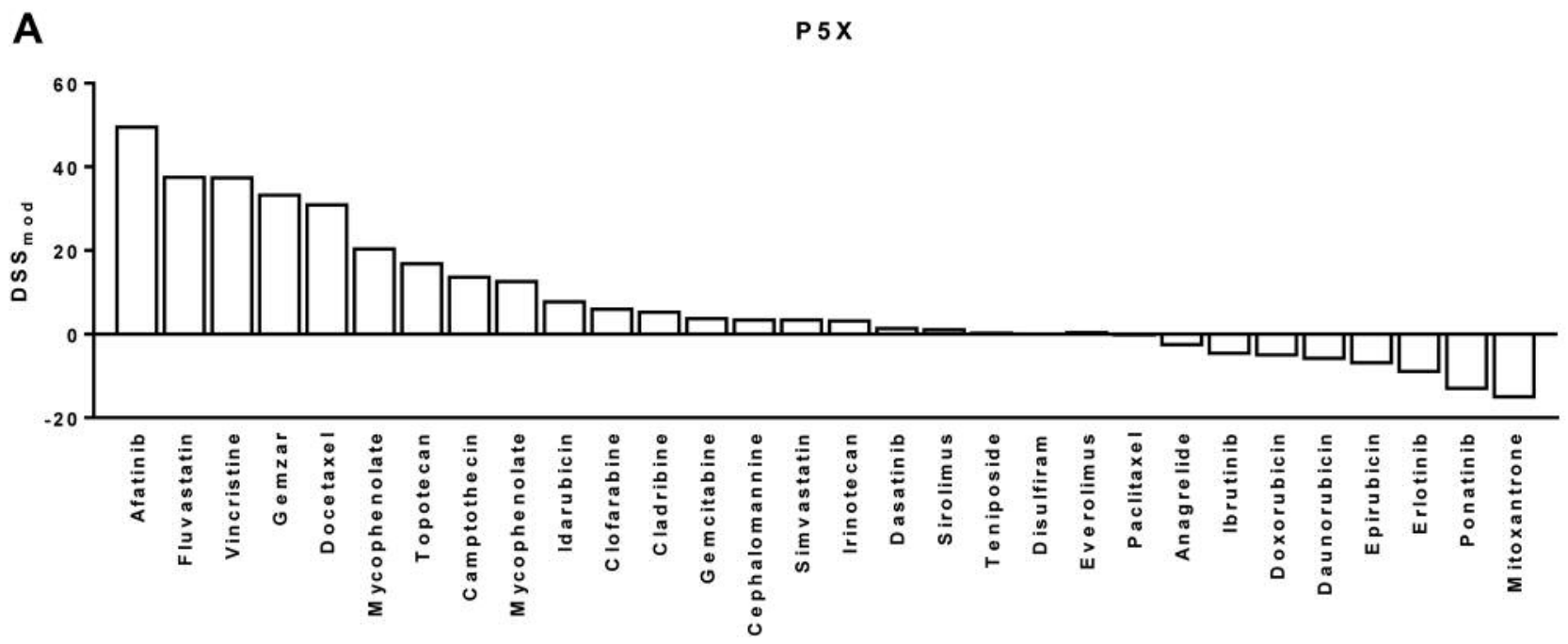

B

P9A1

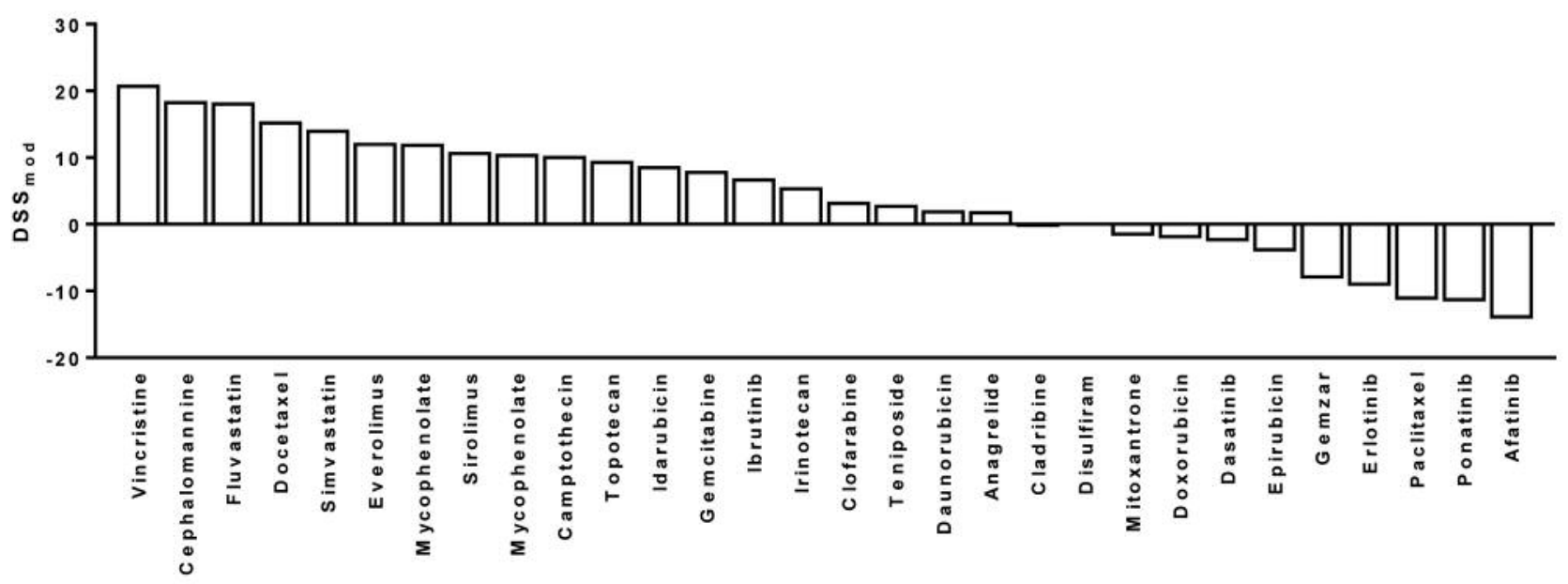

Figure 3. Individual screening results. Bar graphs of clinically actionable drug responses for the papillary serous cancer cell lines P5X (A) and P9A1 (B).

to the remaining compounds varied between the cell lines without any clear clustering based on subtype as shown in response to treatment with gemcitabine (Figure $1 \mathrm{~A}$ and $\mathrm{C}$ ). While the two clear-cell subtypes cluster together based on treatment response, this was not observed with the endometrioid and papillary serous cell lines (Figure 1A). Indeed, the endometrioid and papillary cell lines displayed vastly different treatment responses, further emphasizing the heterogeneity in treatment response between tumors of the same histological subtype (Figure 1A and Table I).

Antimitotics (cephalomannine, docetaxel, paclitaxel and vincristine) (Table I) display efficacy against all of the tested cell lines. Docetaxel, specifically, was one of the most effective compounds in 5/6 of the tested lines, although most lines showed sensitivity to two or more compounds of this class (Figure 1A and B). Paclitaxel, however, was only effective against C1P and CX5 (Figure 1A, Table I). A number of topoisomerase $1 / 2$ inhibitors (Table I) displayed activity in the tested cell lines, although these compounds did not cluster together and no single compound was active in all of the models (Figure 1A) nor in both cell lines of the same histological subtype. Even in cases of compounds that led to responses in all tested cell lines, such as vincristine, the magnitude of response was vastly different. Vincristine was one of the top compounds against P9A1, C5X and P5X, while more active treatment was suggested for E3X, C1P and E1P (Figure 1A and Table I). Responses were specifically low in the endometrioid cell lines (Table I). 
A $\quad$ C1P
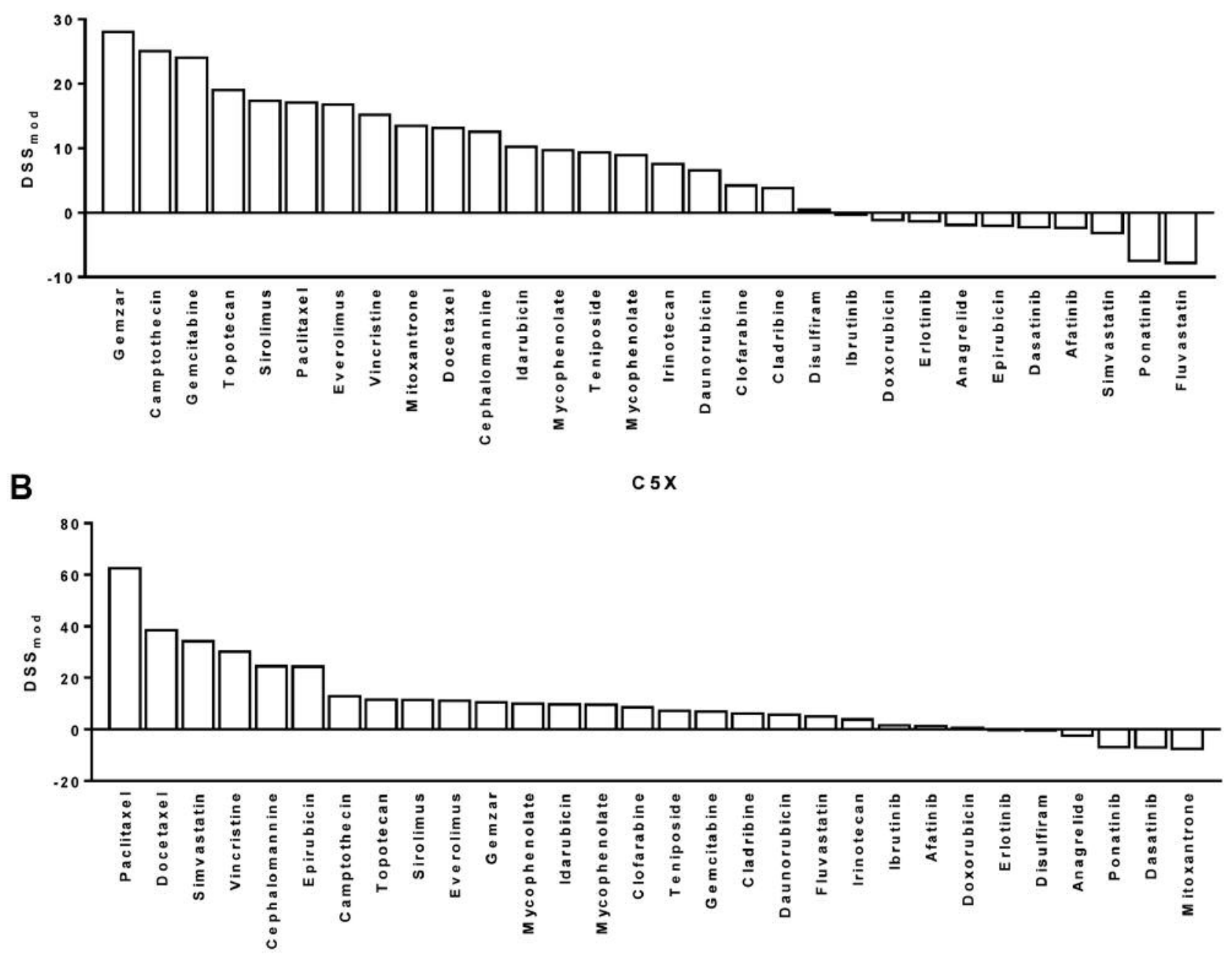

Figure 4. Individual screening results. Bar graphs of clinically actionable drug responses for clear-cell cancer cell lines C1P (A) and C5X (B).

When comparing the cell lines of the individual subtypes, the cell lines responded to different numbers of tumorspecific active drugs ranging from 26 in EP1 cells to 13 in EX3 cells (Figures 2-4). Docetaxel had the highest efficacy against both endometrioid cell lines $(p \leq 0.0001)$ (Figures $1 \mathrm{~B}$ and 2). The other subtypes showed no such similarities in the top candidate treatment suggestions (Figure 3 and 4). Nevertheless, similar treatment responses were observed to compounds displaying low tumor specificity $\left(\mathrm{sDSS}_{\mathrm{mod}}\right)$ (Table I). The clear-cell lines, C1P and C5X, both displayed moderate treatment responses towards the rapalogs everolimus and sirolimus, although more efficient treatment options are available for both cell lines. Responses to gemcitabine on the other hand were significantly different in these lines $(p \leq 0.0001)$ (Figure 1C). While Gemzar (gemcitabine) was the most active against C1P cells (Figure
4A), it elicited only low treatment responses in C5X cells, where it was 17 th (Figure 4B).

The papillary serous cell lines, P5X and P9A1, displayed opposite responses to afatinib. While afatinib was the top candidate against P5X (Figure 3A), it displayed the least tumor specificity against P9A1 (Figure 3B). Fluvastatin on the other hand elicited high treatment responses in both papillary serous cell lines.

\section{Discussion}

Ovarian cancer accounts for more deaths than any other cancer of the female reproductive system, and is more prevalent in older woman. Despite extensive research efforts over the past decade, overall 5-year survival has remained low $(1,2,21)$. This is specifically problematic in older 
patients, a population that generally shows rapid disease progression, in combination with poor overall health and low tolerance to systemic anticancer treatments.

We adapted a precision medicine platform originally developed for use in AML (15) for use in ovarian cancer. This ex vivo drug-sensitivity screening platform can be used to assign patient-specific treatment options without delaying patient treatment. In order to compensate for the lower number of cells available from ovarian cancer surgical samples, we selected 30 FDA-approved agents, most of which are available for compassionate use in patients with ovarian cancer and are not used routinely in ovarian cancer treatment, as a representative set to validate this approach.

We observed a wide range of treatment responses in the patient-derived and established ovarian cancer cell lines evaluated in this study. These results further emphasize the need for personalized treatment strategies for patients with ovarian cancer.

Antimitotics in our panel led to the highest treatment responses in combination with high levels of treatment specificity. Taxanes (docetaxel, paclitaxel) are FDAapproved for use in ovarian cancer and are commonly used clinically. Vincristine and cephalomannine, while used against ovarian cancer, are not part of the standard clinical routine. Nevertheless, both compounds displayed high activity and should be further considered. The remaining compounds showed activity in only a subset of the tested patient-derived cell lines, showing resistance in others. We did not observe any clustering of ovarian cancer subtypes based on the treatment response towards the tested panel, suggesting that the histological classification of these tumors cannot be used as a basis for treatment decisions, although using only two lines per classification, this result needs to be experimentally verified in a larger cohort. DST of individual patients with available surgical samples may be a new avenue for the stratification of patients with ovarian cancer and may reduce the number of unsuccessful treatment attempts and increase survival of patients with platinumresistant disease.

A precision medicine approach using ex vivo drugsensitivity screening holds the potential to greatly improve patient outcomes, especially in a population where multiple, continuous treatments are not an option. Future studies will aim to transition the platform to use fresh biopsies or surgical samples in order to establish a clinically viable workflow that allows for rapid decision making and treatment start. Similarly to platinum therapy, ovarian tumors are likely to develop resistance to DST-directed treatment after an initial response. While it is possible to acquire a follow-up sample in those with hematological cancers such as AML, this is not easy in those with solid tumors where a surgical sample is necessary for DST, making it difficult to re-evaluate the drug sensitivity of relapsed tumor. Additionally, little information is available on how resistance to treatments that are not currently standard of care influence tumor cell sensitivity towards other treatment modalities. These issues will need to be addressed in pilot trials in order to successfully transition the platform. The integration of normal tissue responses as a measure of toxicity to healthy tissue is beneficial for patients, specifically in cases with comorbidities or poor overall health. However, little information is available about the toxicity of the majority of compounds to normal ovarian epithelium or the impact of age and ethnicity on drug response. Because matched normal control samples are rarely available for patients with cancer, it will be necessary to establish a specific panel of normal control tissues for use in ovarian cancer patient testing.

\section{Funding}

SB received support from the National Institutes of Health (R01NS092671 and R01MH110441) and the Jay Weiss Institute for Health Equity. CW's laboratory is currently funded by NIH grants DA035592, DA035055 and AA023781, and Florida Department of Health grants 6AZ08 and 7AZ26. HAA received support from the National Institutes of Health (NS100531) and the Wallace H. Coulter Foundation. TAI is supported by grants from Breast Cancer Research Foundation (BCRF), NCI (R33CA214310) and Department of Defense (DoD) Ovarian Cancer Research Program (OCRP) grant (OC130649).

\section{Conflicts of Interest}

The Authors have no conflicts of interest to declare in regard to this study.

\section{Authors' Contributions}

IL performed the experiments, analyzed the data and wrote the first draft of the article. DJA, C-HV performed the experiments and edited the article. HAA analyzed, quality controlled the data and edited the article. SPB, TAI and CW conceptualized the project, oversaw the experiments and edited the article. TAI generated the cell lines.

\section{Acknowledgements}

Some of this work was supported by the Sylvester Cancer Center Molecular Therapeutics Shared Resource (MTSR).

\section{References}

1 Cronin KA, Ries LA and Edwards BK: The surveillance, epidemiology, and end results (seer) program of the national cancer institute. Cancer 120(Suppl 23): 3755-3757, 2014. PMID: 25412387. DOI: $10.1002 /$ cncr.29049

2 American Cancer Society. Cancer Facts \& Figures 2019. Atlanta: American Cancer Society; 2019.

3 Cole AL, Austin AE, Hickson RP, Dixon MS and Barber EL: Review of methodological challenges in comparing the 
effectiveness of neoadjuvant chemotherapy versus primary debulking surgery for advanced ovarian cancer in the united states. Cancer Epidemiol 55: 8-16, 2018. PMID: 29758492. DOI: $10.1016 /$ j.canep.2018.05.003

4 DiSilvestro P and Alvarez Secord A: Maintenance treatment of recurrent ovarian cancer: Is it ready for prime time? Cancer Treat Rev 69: 53-65, 2018. PMID: 29908480. DOI: 10.1016/ j.ctrv.2018.06.001

5 Morgan RD, Clamp AR, Evans DGR, Edmondson RJ and Jayson GC: Parp inhibitors in platinum-sensitive high-grade serous ovarian cancer. Cancer Chemother Pharmacol 81(4): 647-658, 2018. PMID: 29464354. DOI: 10.1007/s00280-018-3532-9

6 Mariappan L, Jiang XY, Jackson J and Drew Y: Emerging treatment options for ovarian cancer: Focus on rucaparib. Int $\mathbf{J}$ Womens Health 9: 913-924, 2017. PMID: 29290694. DOI: 10.2147/IJWH.S151194

7 Volpe J, Filipi JG, Cooper OR and Penson RT: Frontline therapy of ovarian cancer: Trials and tribulations. Curr Opin Obstet Gynecol 30(1): 1-6, 2018. PMID: 29251676. DOI: 10.1097/ GCO.0000000000000434

8 Cortez AJ, Tudrej P, Kujawa KA and Lisowska KM: Advances in ovarian cancer therapy. Cancer Chemother Pharmacol 81(1): 1738, 2018. PMID: 29249039. DOI: 10.1007/s00280-017-3501-8

9 Ledermann JA: Front-line therapy of advanced ovarian cancer: New approaches. Ann Oncol 28(suppl_8): viii46-viii50, 2017. PMID: 29232475. DOI: 10.1093/annonc/mdx452

10 Pignata S, S CC, Du Bois A, Harter P and Heitz F: Treatment of recurrent ovarian cancer. Ann Oncol 28(suppl_8): viii51-viii56, 2017. PMID: 29232464. DOI: $10.1093 /$ annonc/mdx 441

11 Smith FO: Personalized medicine for AML? Blood 116(15): 2622-2623, 2010. PMID: 20947687. DOI: 10.1182/blood-201007-296418

12 Kuusanmaki H, Dufva O, Parri E, van Adrichem AJ, Rajala H, Majumder MM, Yadav B, Parsons A, Chan WC, Wennerberg K, Mustjoki $\mathrm{S}$ and Heckman CA: Drug sensitivity profiling identifies potential therapies for lymphoproliferative disorders with overactive JAK/STAT3 signaling. Oncotarget 8(57): 9751697527, 2017. PMID: 29228628. DOI: 10.18632/oncotarget. 22178

13 Pemovska T, Kontro M, Yadav B, Edgren H, Eldfors S, Szwajda A, Almusa H, Bespalov MM, Ellonen P, Elonen E, Gjertsen BT, Karjalainen R, Kulesskiy E, Lagstrom S, Lehto A, Lepisto M, Lundan T, Majumder MM, Marti JM, Mattila P, Murumagi A, Mustjoki S, Palva A, Parsons A, Pirttinen T, Ramet ME, Suvela M, Turunen L, Vastrik I, Wolf M, Knowles J, Aittokallio T, Heckman CA, Porkka K, Kallioniemi O and Wennerberg K: Individualized systems medicine strategy to tailor treatments for patients with chemorefractory acute myeloid leukemia. Cancer Discov 3(12): 1416-1429, 2013. PMID: 24056683. DOI: 10.1158/2159-8290.CD-13-0350
14 Staib P, Staltmeier E, Neurohr K, Cornely O, Reiser M and Schinkothe T: Prediction of individual response to chemotherapy in patients with acute myeloid leukaemia using the chemosensitivity index ci. Br J Haematol 128(6): 783-791, 2005. PMID: 15755281 DOI: 10.1111/j.1365-2141.2005.05402.x

15 Swords RT, Azzam D, Al-Ali H, Lohse I, Volmar CH, Watts JM, Perez A, Rodriguez A, Vargas F, Elias R, Vega F, Zelent A, Brothers SP, Abbasi T, Trent J, Rangwala S, Deutsch Y, Conneally E, Drusbosky L, Cogle CR and Wahlestedt C: Exvivo sensitivity profiling to guide clinical decision making in acute myeloid leukemia: A pilot study. Leuk Res 64: 34-41, 2018. PMID: 29175379. DOI: 10.1016/j.leukres.2017.11.008

16 Yadav B, Pemovska T, Szwajda A, Kulesskiy E, Kontro M, Karjalainen R, Majumder MM, Malani D, Murumagi A, Knowles J, Porkka K, Heckman C, Kallioniemi O, Wennerberg $\mathrm{K}$ and Aittokallio T: Quantitative scoring of differential drug sensitivity for individually optimized anticancer therapies. Sci Rep 4: 5193, 2014. PMID: 24898935. DOI: 10.1038/srep05193

17 Villman K, Blomqvist C, Larsson R and Nygren P: Predictive value of in vitro assessment of cytotoxic drug activity in advanced breast cancer. Anticancer Drugs 16(6): 609-615, 2005. PMID: 15930887.

18 Yamada S, Hongo T, Okada S, Watanabe C, Fujii Y and Ohzeki $\mathrm{T}$ : Clinical relevance of in vitro chemoresistance in childhood acute myeloid leukemia. Leukemia 15(12): 1892-1897, 2001. PMID: 11753610.

19 Ince TA, Sousa AD, Jones MA, Harrell JC, Agoston ES, Krohn M, Selfors LM, Liu W, Chen K, Yong M, Buchwald P, Wang B, Hale KS, Cohick E, Sergent P, Witt A, Kozhekbaeva Z, Gao S, Agoston AT, Merritt MA, Foster R, Rueda BR, Crum CP, Brugge JS and Mills GB: Characterization of twenty-five ovarian tumour cell lines that phenocopy primary tumours. Nat Commun 6 : 7419, 2015. PMID: 26080861. DOI: $10.1038 /$ ncomms 8419

20 Merritt MA, Bentink S, Schwede M, Iwanicki MP, Quackenbush J, Woo T, Agoston ES, Reinhardt F, Crum CP, Berkowitz RS, Mok SC, Witt AE, Jones MA, Wang B and Ince TA: Gene expression signature of normal cell-of-origin predicts ovarian tumor outcomes. PLoS One 8(11): e80314, 2013. PMID: 24303006. DOI: 10.1371/journal.pone.0080314

21 Meinhold-Heerlein I and Hauptmann S: The heterogeneity of ovarian cancer. Arch Gynecol Obstet 289(2): 237-239, 2014. PMID: 24318356. DOI: 10.1007/s00404-013-3114-3

Received May 1, 2019

Revised May 28, 2019

Accepted June 6, 2019 